\title{
"I would like to be part of the team distributing the kits because I have all the qualities" Formative research to inform the development of a peer-led HIV self-testing intervention to improve HIV testing uptake and linkage to HIV care among young people and adult men in Kasensero fishing community, Rakai, Uganda
}

Joseph KB Matovu ( $\square$ matovujkb@gmail.com )

Makerere University School of Public Health https://orcid.org/0000-0001-6480-2940

Aminah Nambuusi

Makerere University School of Medicine

Scovia Nakabirye

Makerere University School of Public Health

David Serwadda

Makerere University School of Public Health

Rhoda Wanyenze

Makerere University School of Public Health

\section{Research}

Keywords: Peer-led, HIV, self-testing, fishing community

Posted Date: May 19th, 2020

DOI: https://doi.org/10.21203/rs.3.rs-28819/v1

License: (c) (1) This work is licensed under a Creative Commons Attribution 4.0 International License.

Read Full License 


\section{Abstract}

\section{Background}

Despite efforts to improve HIV testing and linkage to HIV care among young people and adult men, uptake rates remain below global targets. We conducted formative research to generate data necessary to inform the design of a peer-led HIV self-testing (HIVST) intervention intended to improve HIV testing uptake and linkage to HIV care among young people and adult men in Kasensero fishing community in rural Uganda.

\section{Methods}

This was a cross-sectional, qualitative study conducted in three study communities in Kasensero fishing community in Rakai district, Uganda, between May 6 - 10, 2019. Six single-sex focus group discussions (FGDs) comprising 7-8 participants were conducted with young men (15-24 years), young women (15-24 years) and adult men (25+ years). We collected data on people's perceptions about HIVST and peer-led HIVST; potential acceptability of peer-led HIVST and suggestions on how to implement peer-led HIVST in the community. Peer-led HIVST was defined as an approach that uses a trained lay person to distribute HIVST kits to other people in the community. FGDs were audio-recorded with permission from the participants, transcribed verbatim and analysed manually following a thematic framework approach.

Results

Forty-seven participants (31 men and 16 women) participated in the FGDs. Across communities and agegroups, most participants mentioned that peer-led HIVST would be generally acceptable to people in the community but people will need support in performing the test due to fear of performing the test wrongly or failing to cope with HIV-positive results. Most participants felt that peer-led HIVST would bring HIV testing services closer to the community "because [the peer-leader] could be my immediate neighbour", making it easier for people to obtain the kits at any time of their convenience as opposed to placing them at a health facility. Participants suggested that the peer-leader should be a permanent resident, accessible, trustworthy, and good at keeping secrets.

Conclusion

Our study shows that peer-led HIVST is potentially acceptable in the fishing community suggesting that this approach can help to improve uptake of HIV testing services among young people and adult men who are usually missed through conventional HIV testing services.

\section{Introduction}

Reaching young people and adult men with HIV testing services is critical for the attainment of the first "90\%" of the UNAIDS global targets dubbed $90-90-90$ : that is, by $2020,90 \%$ of all people living with HIV will know their HIV status; $90 \%$ of all people with diagnosed HIV infection will receive sustained 
antiretroviral therapy; and $90 \%$ of all people receiving antiretroviral therapy will have viral suppression [1]. However, uptake of HIV testing services and subsequent linkage to HIV care among young people and adult men remain critically below threshold levels particularly in sub-Saharan Africa (SSA) [2]. Studies show that individuals aged 15-24 years are less likely to be aware of their HIV status, to be enrolled in HIV care and to have a suppressed viral load when compared to HIV-positive persons aged 30 years or older [3, 4]. Several barriers continue to inhibit young people from utilizing HIV testing services including low HIV risk-perception [5], long waiting times at HIV testing clinics [6], concerns around confidentiality of HIV test results by health workers [7] and fear of knowing their HIV status [8, 9]. These findings call for a need to design interventions that can mitigate these barriers while improving HIV testing and linkage to HIV care among young people.

Across SSA, current interventions to increase men's uptake of HIV testing services are lacking. A recent systematic review of strategies to increase men's HIV testing rates in SSA showed that few HIV interventions targeted men specifically [10]. As a result, men are less likely to test for HIV, more likely to enrol into HIV care with advanced HIV disease and more likely to be lost to follow-up or to die earlier than women, presumably because of late enrolment into HIV care $[2,11]$. It is probably for this reason that UNAIDS, in 2017, dubbed men and boys as the "blind spot" in the HIV response [2]. While previous interventions aimed at increasing HIV testing among men have been relatively successful [12-16], uptake of HIV testing services among men remain generally below the $90 \%$ threshold. Hegemonic masculinity norms that deter men from accessing health facility-based HIV services [17-19] have been implicated as the leading cause of men's low uptake of HIV testing and treatment services, particularly those provided at health facilities. Studies have found that men visit primary care facilities less frequently than women, have fewer preventive health checks and when they seek medical help, ask fewer questions than women [2]. In order to improve HIV testing rates among young people and adult men, it may be necessary to utilize approaches that are acceptable to them and other members of their social networks [20, 21]. However, little evidence exists on how best such interventions can be designed or implemented to reach these populations that are usually missed through conventional HIV testing services. This paper presents findings from a formative study conducted to generate data necessary to inform the design of a peer-led HIV self-testing intervention intended to improve HIV testing uptake and linkage to HIV care (among firsttime HIV-positive individuals) in Kasensero fishing community in rural Uganda.

\section{Methods}

\section{Study site}

The study was conducted in Kasensero, a hyperendemic fishing community, along the shores of Lake Victoria in Rakai district. Kasensero fishing community has the highest HIV prevalence in Uganda with average adult HIV prevalence ranging between $37-41 \%$ [22-25]. The fishing community is composed of three study communities, namely: Kasensero landing site, Gwanda and Kyebe. Almost $90 \%$ of the residents of Kasensero landing site are engaged in fishing or fishing-related activities (e.g. net repairing, boat making/repairing; fish drying and fish vending) although people engage in other occupations 
including farming, boda-boda riding, operating restaurants, and engaging in business activities, among other activities, particularly as one moves away from the landing site [26]. The fisher-folk population is unique in multiple respects: they tend to migrate between landing sites in search of fish as the fish season changes; and the fishermen tend to spend a number of days on the lake which denies them access to health services, including HIV testing and linkage to HIV care [27]. Besides, the fishing crews generally work during the night hours and collect the fish in the early morning. Thus, if they are not fishing, they are idle during the day and tend to spend time consuming alcohol and engaging in sexual activity since there are few recreational services on the Lake shores.

\section{Study design}

This was a cross-sectional, qualitative study that was conducted as part of a large study intended to assess the effect of a peer-led HIV self-testing intervention on HIV testing uptake and linkage to HIV care among young people (15-24 years) and adult men ( $25+$ years) in Kasensero fishing community.

\section{Participant selection}

Study participants were selected working closely with community health mobilizers. We obtained lists of existing community health mobilizers from the Rakai Health Sciences Program; a research organization that conducts health research in Rakai district, including in Kasensero fishing community. A staff of the Rakai Health Sciences Program helped to introduce members of the study team to at least one community health mobilizer in each study community who then introduced them to other community health mobilizers in the community. A week to the focus group discussion (FGD), the study team contacted community health mobilizers in each community and asked them to identify a venue for the FGD and invite participants to attend the FGD on a pre-determined date. Community mobilizers were asked to identify participants, stratified by age-group into young men (15-24 years), young women (1524 years) and adult men, depending on the type of FGD that had been allocated to a particular community (see Table 1 below). Because we intended to gain insight into how many social network groups existed in the community, we asked the community health mobilizers to ensure that each FGD included people who belonged to as many social network groups as those that they knew themselves.

Prior to each FGD, we conducted preliminary screening for eligibility based on age, and those who were below or above the age-category allocated to a particular community were excluded from the FGD. For young people aged 15-17 years (technically known as 'minors'), we inquired to determine if they were 'emancipated minors' (e.g. whether or not they were married or lived an independent life away from their parents) and only those that were considered to be emancipated were included into the FGD, after consultations with the community health mobilizers.

\section{Data collection procedures and methods}

Six FGDs were conducted to collect data from the three study communities using a FGD guide. Of these, two FGDs were conducted at Kasensero landing site; 2 FGDs were conducted in Gwanda and the other two FGDs were conducted in Kyebe, as summarized in Table 1 below. The FGDs were age- and sex- 
stratified in such a way that two FGDs were conducted with young men (15-24 years); two FGDs were conducted with young women (15-24 years) and two FGDs were conducted with adult men ( $25+$ years). FGDs were composed of between 7-8 participants drawn from different interest groups. Data were collected on a priori themes (see 'Data analysis' below) by two senior Social Scientists in the local language (Luganda) and were audio-recorded with permission from the participants. FGDs took between 1-2 hours. Participants were compensated for the time taken in participating in the FGDs ( US\$2).

Table 1

Composition of FGDs conducted in Kasensero fishing community

\begin{tabular}{|c|c|c|c|}
\hline $\begin{array}{l}\text { FGD } \\
\text { No. }\end{array}$ & $\begin{array}{l}\text { Study } \\
\text { Community }\end{array}$ & $\begin{array}{l}\text { Participants' } \\
\text { characteristics }\end{array}$ & Group composition \\
\hline 1 & Kasensero & $\begin{array}{l}\text { Adult men }(25 \\
+ \text { years })\end{array}$ & $\begin{array}{l}\text { Of the eight participants, six }(6) \text { were fishermen, one }(1) \text { was } \\
\text { a boat pusher while the remaining participant was a boat } \\
\text { engineer }\end{array}$ \\
\hline 2 & Kasensero & $\begin{array}{l}\text { Young women } \\
\text { (18-24 years) }\end{array}$ & $\begin{array}{l}\text { Of the eight participants, one (1) was a hair dresser, one (1) } \\
\text { was a sex worker, one (1) was a vegetable vendor, one (1) } \\
\text { was a drug shop attendant, one (1) was a tailor while three } \\
\text { (3) were house wives. }\end{array}$ \\
\hline 3 & Gwanda & $\begin{array}{l}\text { Young men } \\
\text { (18-24 years) }\end{array}$ & $\begin{array}{l}\text { Of the eight participants, four (4) were boda-boda cyclists, } \\
\text { one (1) was a student, one (1) was a bricklayer, one (1) was } \\
\text { a motorcycle mechanic and one (1) was a farmer }\end{array}$ \\
\hline 4 & Gwanda & $\begin{array}{l}\text { Young women } \\
\text { (18-24 years) }\end{array}$ & $\begin{array}{l}\text { Of the eight participants, six were trainees in the DREAMS } \\
\text { project and two were housewives }\end{array}$ \\
\hline 5 & Kyebe & $\begin{array}{l}\text { Adult men }(25 \\
+ \text { years })\end{array}$ & $\begin{array}{l}\text { Of the seven participants, one (1) was a casual labourer, one } \\
\text { (1) was a Security Guard while five (5) were farmers. }\end{array}$ \\
\hline 6 & Kyebe & $\begin{array}{l}\text { Young men } \\
\text { (18-24 years) }\end{array}$ & $\begin{array}{l}\text { Of the eight participants, five (5) were boda-boda cyclists, } \\
\text { two (2) were farmers and one (1) was a shopkeeper }\end{array}$ \\
\hline
\end{tabular}

\section{Data analysis}

All FGD interviews were transcribed verbatim and translated into the English language prior to analysis. Transcribed interview data were entered into a Microsoft Word processing document and later printed out in preparation for data analysis. Data were analysed deductively following the six phases of thematic framework analysis suggested by Braun and Clarke [28]. Initially, AN and SC transcribed the data and typed them into Microsoft Word documents. JKBM, AN and SC read through printed copies of the transcripts to ensure completeness of transcription while comparing them with the audio-recordings and the questions in the FGD guide. Once this process had been completed, AN and SC read through three of the six transcripts to generate codes based on nine a priori themes, i.e. i) willingness to use HIVST; ii) concerns about HIVST; iii) nature of support that people would need to properly perform HIVST and interpret their results correctly; iv) perceptions about peer-led HIVST; v) potential acceptability of a peerled HIVST intervention in the community; vi) willingness for people to accept to receive HIV self-test kits from a peer-leader; vii) existing social network groups; viii) how HIV self-test kits could be distributed within existing groups, and ix) qualities of peer-leaders. Once this was finalized, JKBM and AN analysed 
the list of codes to decide which codes belonged to what themes, and if any codes belonged to more than one theme. This process resulted in a final list of codes that were aligned to specific themes. A few codes appeared to be cross-cutting; these were not allocated to any specific a priori themes. We then reviewed the final list of codes assigned to each theme to determine which themes had enough data to stand on their own and which ones had little data that they needed to be merged with others.

At the end of this iterative process, the initial nine a priori themes were grouped into four overarching themes, namely: i) perceptions on HIVST; ii) potential acceptability of peer-led HIV self-testing; iii) existing social network groups; and iv) how to distribute HIVST kits within existing social networks. We continued to review these themes to ensure that they clearly defined what we intended to explore about each theme and identified relevant quotations to support each theme. This paper is based on the four themes that were determined through the above-mentioned iterative process.

\section{Results}

\section{Participants' characteristics}

Table 2 shows the socio-demographic characteristics of the 47 participants ( 31 men and 16 women) that participated in the FGDs. Overall, 68.1\% were young people aged $18-24$ years $(n=32) ; 19.1 \%(n=9)$ were aged $25-34$ years and $12.8 \%(n=6)$ were aged $35+$ years. No women were aged $25+$ years in line with the study design. Slightly more than half of the men $(51.1 \%, n=24)$ had attended school up to upper primary level of education (P5-P7) while $29.7 \%(n=14)$ had attended school up to lower secondary education level (S1-S4), suggesting that $38(80.8 \%)$ of the 47 participants had attended upper primary or post-primary education. 
Table 2

Socio-demographic characteristics of FGD participants

\begin{tabular}{|c|c|c|c|}
\hline Characteristic & $\begin{array}{l}\text { Men }[N=31] \\
(n, \%)\end{array}$ & $\begin{array}{l}\text { Women }[N=16] \\
(n, \%)\end{array}$ & $\begin{array}{l}\text { Total }(\mathrm{N}=47) \\
(\mathrm{n}, \%)\end{array}$ \\
\hline Age-group & $16(51.6)$ & $16(100.0)$ & $32(68.1)$ \\
\hline $18-24$ & $9(29.0)$ & $0(0.0)$ & $9(19.1)$ \\
\hline $25-34$ & $6(19.4)$ & $0(0.0)$ & $6(12.8)$ \\
\hline \multicolumn{4}{|l|}{$35+$} \\
\hline Education & $1(3.2)$ & $1(6.3)$ & $2(4.3)$ \\
\hline None & $5(16.1)$ & $1(6.3)$ & $6(12.8)$ \\
\hline Lower Primary (P1-P4) & $17(54.8)$ & $7(43.7)$ & $24(51.1)$ \\
\hline Upper Primary (P5-P7) & $7(22.6)$ & $7(43.7)$ & $14(29.7)$ \\
\hline Lower Secondary (S1-S4) & $1(3.2)$ & $0(0.0)$ & $1(2.1)$ \\
\hline \multicolumn{4}{|l|}{ Upper Secondary (S5-S6) } \\
\hline Marital status & $10(32.3)$ & $0(0.0)$ & $10(21.3)$ \\
\hline Single/Never married & $13(41.9)$ & $7(43.7)$ & $20(42.6)$ \\
\hline Currently married & $1(3.2)$ & $0(0.0)$ & $1(2.1)$ \\
\hline $\begin{array}{l}\text { Ever married but not currently married } \\
\text { In a relationship but not married }\end{array}$ & \multicolumn{2}{|c|}{ In a relationship but not married } & $16(34.0)$ \\
\hline Prior HIV testing history & $28(90.3)$ & $16(100)$ & $44(93.6)$ \\
\hline Ever tested for HIV & $3(9.7)$ & $0(0.0)$ & $3(6.4)$ \\
\hline \multicolumn{4}{|l|}{ Never tested for HIV } \\
\hline Length of stay in the community & $0(0.0)$ & $3(18.7)$ & $3(6.4)$ \\
\hline$<1$ year (less than 12 months) & $1(3.2)$ & $2(12.5)$ & $3(6.4)$ \\
\hline $1-2$ years & $30(96.8)$ & $11(68.8)$ & $41(87.2)$ \\
\hline \multicolumn{4}{|l|}{$3+$ years } \\
\hline Occupation & $8(25.8)$ & $0(0.0)$ & $8(17.0)$ \\
\hline $\begin{array}{l}\text { Fishing/Fishing-related activities } \\
\text { Other occupation }\end{array}$ & $23(74.2)$ & $16(100)$ & $39(83.0)$ \\
\hline
\end{tabular}


A slightly higher proportion of females reported that they had attended school up to lower secondary education than males (43.7\% vs. $22.6 \%)$. A majority of the participants $(42.6 \%, n=20)$ were currently married while $34.0 \%(n=16)$ were engaged in a sexual relationship but not currently married. Almost similar proportions of men $(41.9 \%)$ and women $(43.7 \%)$ reported that they were currently married although there were more females $(56.3 \%, \mathrm{n}=9)$ that reported being in a sexual relationship but not married than men $(22.6 \%, n=7)$. Almost all participants $(93.6 \%, n=44)$ had ever tested for HIV, although this proportion was slightly lower among men $(90.3 \%, n=28)$ than women $(100 \%)$. Eighty-seven per cent of the participants had stayed in the community for three or more years, with a higher proportion of men reporting that they had stayed in the community for three or more years than females (men: $96.8 \%, n=30$; women: $68.8 \%, n=11)$. By occupation, majority of the participants $(83.0 \%, n=39)$ were engaged in other occupations other than fishing or fishing-related activities.

\section{Perceptions about HIVST, potential acceptability of peer-led HIVST and distribution of HIVST kits in existing social network groups}

As already noted, study findings were organized into four themes: a) perceptions about HIV self-testing as an alternative HIV testing strategy in general; b) potential acceptability of a social network-based, peer-led HIV self-testing program; c) existing social networks in the community; and d) how to distribute HIV selftest kits to members in a social network. Each of these themes is presented in the following sub-sections.

\section{a) Perceptions about HIVST as an alternative HIV testing strategy}

In general, all participants had favourable attitudes towards HIVST with most participants reporting that HIVST is easy to perform; it offers an opportunity for busy people, who do not have the time to go to health facilities, to test for HIV and, most importantly, it takes away the need to incur travel costs to access health facility-based HIV testing services:

According to me, the way I see myself and my fellow young people, they [people] will be willing to use HIV self-test kits because in most cases they are busy working so they do not get time to go to health centres for HIV testing and usually health centres are far requiring around UGX 2000-3000 [ US\$ 0.5-0.8] for transport and yet I can spend a month without getting that money so if we are given those kits, it will help us to know our HIV status (Young men, Gwanda)

While participants liked the fact that HIV self-testing can be conducted outside formal health facility settings, they were quick to point out that individuals who receive HIV-positive self-test results should go to the health facilities to have their results confirmed. This is important given the apparent fears that people who self-test HIV-positive may not have the motivation to seek confirmatory HIV testing services in order to start on HIV treatment if confirmed as HIV-positive:

HIV self-testing is a very good intervention. If you bring HIV self-test kits, we are willing to use them because they will minimize the problem of having to line up for HIV testing services and yet sometimes 
you are scared of the health worker giving you the results. But with self-test kits one tests alone [and he/shel can know whether he/she is positive or not and in case he/she is HIV negative, he/she decides to protect him/herself and if HIV positive, he/she can go to the health center and get tested again to confirm the HIV status (Young men, Gwanda)

However, despite outlining the benefits of HIVST, there were mixed reactions as to whether one should conduct the test alone or in the presence of someone else that they trust. Those who preferred to test alone reasoned that testing in the presence of someone else could result in one's results being known to other people, especially if the other person fails to keep the results secret. However, most of those who preferred to test in the presence of someone else reasoned that this person can help the self-tester to deal with unexpected results, especially in the event that one's results turn out to be HIV-positive. The latter perspective reinforces the importance of providing pre- and post-test counselling to individuals who selftest for HIV:

Considering what we have just been informed about HIV self-test kits, the whole process of HIV selftesting takes between 20-30 minutes better than all the other methods of HIV testing that we have been using. [However], how will you support yourself if you self-tested positive? Surely there is need of another trained person to be around so that you can be counselled (Adult men, Kasensero)

Indeed, there were concerns that some people might fail to conduct the self-testing exercise correctly if they do it alone, and that HIV self-testing might cause some people to 'hurt themselves', i.e. commit suicide, if they self-tested HIV-positive without anyone to comfort them, as the following quotation illustrates.

My concern is about a person 'hurting' himself if results of HIV self-test are positive. Because he will know his self-test results in a private place, there are higher chances of this person 'hurting' himself. So, if selftesting is done with someone around then such scenarios can be avoided (Adult men, Kasensero)

There were also fears that people who self-test HIV-positive may be reluctant to seek confirmatory HIV testing or enrol into HIV care without the support of someone else especially if they initially thought they were HIV-negative but turned out to be HIV-positive.

My fear is it's very possible for someone to test HIV positive and [he/she] doesn't go to the health facility to seek further HIV care especially if this person thought that he/she is HIV negative and the HIV self-test results show positive. Because he/she was not counselled enough, he/she may be reluctant going to the health facility to seek HIV confirmatory testing and HIV care (Adult men, Kyebe)

When asked how these fears could be minimized, most participants suggested the need to train potential users of HIV self-test kits in how to use the kits; how to interpret their own HIV self-test results, and how to deal with the different types of HIV results before they are given the kits to use. Participants reasoned that such training would help users to self-test with ease and to deal with any associated consequences. 
There were also suggestions that, in addition to the training, users should be encouraged to seek HIV care if HIV-positive or to protect themselves from the risk of HIV infection if HIV-negative.

Before you give him/her that kit, you should educate him/her on how he/she is going to use it to test. If he/she tests positive, you encourage him/her to go to the health center to get treatment. If he/she tests negative, you encourage him/her to protect her/himself that if he/she is going to have sex, he/she should use a condom. (Young men, Kyebe)

\section{b) Potential acceptability of peer-led HIVST}

Besides exploring people's perceptions about HIVST in general, we sought participants' views on peer-led HIVST; an approach where we intended to train local people in the community as 'peer-leaders' who would then distribute HIV self-test kits to members of their social networks. This approach is based on the assumption that people who belong to social networks know each other very well and can be easily reached with HIV testing services if HIV self-test kits were delivered to them by a member of their social network who has been trained in HIVST processes. Participants were particularly asked if such an approach would be acceptable to people in the community, and if so, we sought their opinions on how such an approach could be implemented in a fishing community. In response, most participants felt that the approach would be acceptable to people in the community 'because the person distributing HIV selftest kits could be my immediate neighbour which means he is near and easy to reach, I can easily access HIV self-test kits, go back to my home and do a self-test'. Besides the ease of reaching the peer-leader, participants felt that use of a peer-led approach would make it easier for them to obtain the kits from their peer-leader at any time rather than go to the health facility which has opening and closing times:

I can access them [kits] whenever I want unlike at the health center that closes at 2 pm. But I can knock at that person's door [any time] and tell him/her to give me the kit (Young females, Kasensero)

Most participants reported that peer-led HIVST would help to improve people's ability to test for HIV since the approach is private and ensures confidentiality of HIV test results. This is because the test is done in private and it's upon the tester to disclose his/her results to their peer-leader or someone else. This approach was liked by the participants so much that some of them expressed the need to be selected as peer-leaders, reasoning that they can ably deliver the kits to their social network members and are approachable, social and trustworthy - key qualities necessary of a peer-leader:

I suggest you give HIV self-test kits to me because now I have knowledge about them and I can also explain the test procedures to my group members and distribute the kits to them (Young men, Gwanda)

I would like to be part of the program, however, I am a fisher man and sometimes I fish from far distance from here, where by I spend more than two days in the lake yet you might need someone who is always on the mainland. ... [but] yes, I would like to be part of the team distributing [kits] because I have all the qualities, I am approachable, social and trustworthy (Adult men, Kasensero) 
Since peer-led HIVST seemed acceptable to the participants, we asked them to identify which category of people they would be comfortable obtaining HIV self-test kits from in the community. In response, participants suggested that HIV self-test kits should be given to village health team (VHT) members or peer educators to distribute them to the people in the community.

Most people fear going to health facilities, so I would prefer that they are given to VHTs or peer educators (Adult men, Kyebe)

When asked about what qualities such people should have, participants mentioned that the communitybased HIV self-test kits distributor should be a permanent resident of the area, someone who is not mobile (i.e. who can easily be found within the community at any time); educated to at least ordinary level of education (i.e. senior four); someone who easily relates with others, and most importantly, someone who can keep people's secrets. Some participants suggested that peer-leaders should be trained in how to counsel other people, with emphasis put on how to keep people's secrets:

The person who will be given the kits should be trained first on how he/she should handle people so that he is able to keep people's secrets so that he/she is not a rumourmonger who goes on telling people's secrets to other people (Young men, Kyebe)

$\mathrm{He} /$ she should be friendly with everyone, trustworthy, keeps secrets, a resident who can be accessed any time. He/she should be educated and enlightened. He/she should be able to counsel others (Young women, Gwanda)

Participants were concerned that if the community-based distributor was not good at keeping secrets, they could move in the community telling others how someone picked kits from them; something that could deter people from accepting the kits from them.

\section{c) Existing social networks in the community}

Since the peer-led HIVST program hinges on distribution of HIV self-test kits within social network groupings by a trained peer-leader, we asked participants, through free-listing, to tell us which social network groups exist within their community; and for any existing groups, to tell us if they are 'big' or 'small' groups (the definition of what constitutes 'big' and 'small' was left to the discretion of the participants), and whether or not they were male-only, female-only or of mixed gender. We also inquired of the possibility that some people could belong to several groups within the same community. In summary, a total of 21 social network groups were identified (Table 3); of these, 11 groups were male-only; four groups were female-only, while six groups had membership of both men and women. 
Table 3

Existing social network groupings, stratified by membership gender

\begin{tabular}{|c|c|c|c|c|}
\hline$S / N$ & Social network grouping & $\begin{array}{l}\text { Male } \\
\text { members } \\
\text { only }\end{array}$ & $\begin{array}{l}\text { Female } \\
\text { members only }\end{array}$ & $\begin{array}{l}\text { Both male and } \\
\text { female members }\end{array}$ \\
\hline 1 & Boat pushers & $\sqrt{ }$ & & \\
\hline 2 & Drug user groups & & & $\sqrt{ }$ \\
\hline 3 & $\begin{array}{l}\text { Boda-boda cyclists [commercial } \\
\text { motorcycle riders] }\end{array}$ & $\sqrt{ }$ & & \\
\hline 4 & Local brew drinkers & $\sqrt{ }$ & & \\
\hline 5 & Footballers & $\sqrt{ }$ & & \\
\hline 6 & Netballers & & $\sqrt{ }$ & \\
\hline 7 & Savings/cash-round groups & & & $\sqrt{ }$ \\
\hline 8 & Sex workers & & $\sqrt{ }$ & \\
\hline 9 & Pool table players & $\sqrt{ }$ & & \\
\hline 10 & Talent show groups & & & $\sqrt{ }$ \\
\hline 11 & $\begin{array}{l}\text { Board game and playing card } \\
\text { players }\end{array}$ & $\sqrt{ }$ & & \\
\hline 12 & Family planning groups & & $\sqrt{ }$ & \\
\hline 13 & MSM groups & $\sqrt{ }$ & & \\
\hline 14 & Religious groups & & & $\sqrt{ }$ \\
\hline 15 & Fishermen & $\sqrt{ }$ & & \\
\hline 16 & Farmers groups & & & $\sqrt{ }$ \\
\hline 17 & Betting clubs & $\sqrt{ }$ & & \\
\hline 18 & Unbound group & & & $\sqrt{ }$ \\
\hline 19 & Bricklayers association & $\sqrt{ }$ & & \\
\hline 20 & Motorcycle mechanics group & $\sqrt{ }$ & & \\
\hline 21 & DREAMS $^{\mathrm{a}}$ & & $\sqrt{ }$ & \\
\hline
\end{tabular}


In general, we found that some people belonged to more than one group in the same community. For example, a sex worker could be a member of a savings group and also a netballer. Similarly, boda-boda cyclists could be members of savings groups and also belong to a group of pool table players. However, members seemed to have royalty to specific groups, and when asked which groups they belonged to, they cited one group in preference of the other(s). This information was necessary to inform the selection of peer-leaders and their social network members at the time of implementing the proposed peer-led HIVST intervention.

Our observation was that there were four biggest groups in the three study communities, namely: fishermen, savings/cash-round groups, sex workers and DREAMS. The group of fishermen was composed of men whose primary occupation is fishing; those who do the actual fishing in the lake, and other men involved in fishing-related activities, e.g. boat pushers. Boat pushers are groups of young men whose role is to push the boat from shallow waters to the mainland when fishermen return from a fishing expedition (so that the fish caught can be removed for sale). They also serve to push the boat back to the water when fishermen are setting off for another fishing expedition. Groups of fishermen can have about 500 members or even more.

On the other hand, groups of sex workers comprise all female sex workers who operate at Kasensero landing site under the leadership of a "dealer" or 'pimp' who acts as the 'group manager'. Sex worker groups can have between 30-100 members. The 'dealer' is the person that men approach if they need to get a sex worker but her roles can stretch to resolving conflicts and arbitration between conflicting sex workers. Savings/cash-round groups can be composed of men, women or both men and women and exist to encourage members to save money for a defined purpose, usually under the leadership of a chairperson or group leader. Members contribute money to the group on a weekly basis. A member can borrow money from the group and return it with interest or the members can agree to receive back their savings on a rotational basis. Finally, the DREAMS group is composed of HIV-negative girls who have been enrolled into the DREAMS Project which is implemented by the Rakai Health Sciences Program. Girls enrolled in the DREAMS Project are encouraged to join existing savings groups or form new DREAMS-specific groups, and this is how the DREAMS savings group was created.

"We have "DREAMS Tusitukiremu [Let's Stand Together]" and "Little Angels". Those groups help girls save money every week even if its five hundred, it teaches them how to save. A girl saves the money that she has every week starting from five hundred to ten thousand. After she has acquired skills in tailoring, that money helps her rent a house" (Young women, Kasensero).

\section{d) How to distribute kits in existing social network groups}

After obtaining information about existing social network groups, we asked participants how best HIV self-test kits could be distributed within these networks. Most participants suggested a need to identify someone in the group, or a group leader, who could be trained in HIVST distribution processes and be given HIV self-test kits to take to his/her social network members. 
You should approach the boat pushers and tell them to select a leader, then the leader distributes the test kits to rest of the members (Adult men, Kasensero)

There's someone who heads the DREAMS program, it necessitates training that person because they can easily get to her since she is always around. They should train her so that she is the one that you meet and give the kits to (Young women, Gwanda)

When asked if the person selected to distribute HIV self-test kits to members in a network should be male or female, on the whole, most participants felt that the sex of the distributor did not matter since it is all about obtaining the kits, and all one needs to do is '...to go and tell that person that I need a kit. He/she won't know your results. He/she will just give you the kit and you go to your home to test', except that some young women preferred that the distributor be a man, because women may fail to keep secrets:

"I would like to get it from a man, most women gossip a lot, they don't keep quiet. It's not easy for a man to give it to you and tell another man but with women, the moment you leave, she will tell someone" (Young women, Gwanda)

One interesting finding, which was only identified in one group of young men, was the need to give out kits along with an identifying slip or chit. These young men reasoned that the slips or chits given along with the kits would be important in tracking the number of kits given out and the number of given kits that have been returned. We thought this was a wise idea and we eventually adopted it as part of the planned peer-led HIVST intervention:

Let me [give] an example, we [are] here in this group that has a name, we need slips so that you give out a kit and a paper and after testing, you return the kit to the health worker. That kit should have that person's name... those slips are going to help us note the number of kits that we have given out and the number that has been returned. We will know how many people have been able to know their status (Young men, Kyebe)

\section{Discussion}

Our findings from this formative study of a peer-led HIVST intervention suggest three pertinent issues that can inform future community-based HIVST programs: a) Peer-led HIVST is acceptable among community residents who believe that it is easier to obtain kits from someone that they live with and who they can approach any time to get the kits; $b$ ) existing social network groupings have leaders that can be trained as peer-leaders (or new individuals can be identified within the groups and trained) to distribute HIV selftest kits within their social networks; and c) selected peer-leaders should be approachable, resident in the same community as their social network members and be able to keep secrets. The finding that peer-led HIVST was acceptable was important for the design of the planned peer-led HIVST intervention in which we planned to work with selected local people, train them as peer-leaders, and ask them to distribute HIV self-test kits within their networks. 
Previous research on peer-led HIVST interventions suggests that the use of peer-leaders can be an important attribute in reaching out to members of social networks that may not access conventional HIV services [29,30]. In a pilot trial of the peer-based distribution of HIV self-test kits among fishermen in Bulisa, Uganda, Choko [29] found that $82 \%$ of men who were reached with HIV self-test kits by their peers accepted to self-test for HIV. In another study to assess the effect of peer distribution of HIV self-test kits to men who have sex with men on HIV testing uptake among men with undiagnosed HIV infection in Uganda, Okoboi [30] found that 95\% of the MSM who were reached with fellow MSM with HIV self-test kits accepted to test for HIV. Evidence from prior studies [31, 32], along with our findings, suggest that the use of a peer-led HIVST approach can help to improve uptake of HIV testing services in populations that cannot easily access conventional HIV services either due to their mobility, physical location, sexual orientation or other barriers.

We found that up to 21 social network groups existed in the study communities although there was a high possibility that these were not distinct groups since membership to several groups was possible. Nevertheless, the finding that more organized groups such as those of sex workers and fishermen had identified someone as their leader was an important finding that helped to inform the design of the planned peer-led HIV self-testing intervention. Basing on these findings, we convened meetings with representatives from each group to identify people who could be trained as peer-leaders. We used the qualities identified in this study to characterize the type of people that could be selected and trained as peer-leaders.

This study had a number of limitations. The data were collected using only one method, focus group discussions, thereby affecting our ability to triangulate the findings using different data collection methods. However, we ensured that the participants were drawn from different population groups in the three study communities; thereby increasing the likelihood that the views expressed by these participants reflected practical realities in the different communities. However, since the focus group discussions were conducted before the social network groups were identified, it is likely that we did not get a fair representation of the different groups that existed within the community at the time, thereby affecting the generalizability of findings to all the groups in the fishing community. And, finally, although this study was planned as part of a network-based study, we did not go into the full length and breadth of social network analysis, since this study was intended to identify social network groups for purposes of selecting peer-leaders. For that reason, the data collected about the groups was only that which was needed to inform the design of the intervention and no further attempt was made to collect additional social network data that would be collected in a typical social network study. Despite these limitations, we believe that the study findings provide the impetus for the use of peer-led HIVST programs to target hard-to-reach populations, including fishing communities, and indeed, the findings provided insight into the nature of existing social network groupings in Kasensero fishing community as well as the qualities that selected peer-leaders should have. These aspects were very crucial in the design and implementation of the peer-led HIVST program in Kasensero fishing community. 


\section{Conclusion}

Our study found that peer-led HIVST is a welcome approach in the fishing community given that people can easily access HIV self-test kits from their peer-leaders who live in the same community without the need to travel to the health facilities. Our findings show that peer-leaders should have defined qualities (e.g. able to keep secrets) if the peer-led HIVST program is to be successful. These findings suggest that implementation of peer-led HIVST interventions can be a feasible way of improving uptake of HIV testing services among under-served populations who belong to existing social network groupings.

\section{Declarations}

\section{Ethics approval and consent to participate}

This study was reviewed and approved by the Makerere University School of Public Health's Higher Degrees, Research and Ethics Committee (Protocol \#: 649) and the Yale University School of Public Health Institutional Review Board (Protocol \#: 2000024945) and cleared by the Uganda National Council for Science and Technology. All young men and women below 18 years of age were enrolled only if they were emancipated minors. Emancipated minors were considered to be eligible to provide their own consent without the need for parental/guardian consent, as per guidance from the Uganda National Council for Science and Technology (UNCST).

\section{Consent for publication}

Not applicable

\section{Availability of data and materials}

The datasets generated and/or analysed during the current study are not publicly available due to individual privacy concerns but are available from the corresponding author on reasonable request.

\section{Competing interests}

The authors declare that they have no competing interests

\section{Funding}

This work was implemented as part of JKBM's Post-Doctoral Research Fellowship with a grant from the National Institutes of Health Global Health Equity Scholars Fellowship Program (FIC D43TW010540, PI: Riley LW) and another grant from the Africa Research Excellence Fund (RF-1570024-F-MATOV). The funders had no role in study design, data collection and analysis, decision to publish, or preparation of the manuscript.

\section{Authors' contributions}


JKBM conceived the study, supervised data collection, conducted the data analysis and drafted the manuscript. AN and SN conducted the interviews, transcribed the interviews, and performed the initial data analysis. DS and RW guided the initial conceptualization of the study, provided scientific oversight during study implementation, and reviewed the final manuscript for substantial intellectual content. All authors read and approved the final manuscript.

\section{Acknowledgements}

We acknowledge support from the Rakai Health Sciences Program in the implementation of this study and study participants for participating in this study.

\section{References}

1. UNAIDS, 90-90-90: An ambitious treatment target to help end the AIDS epidemic. Geneva: UNAIDS; 2014. Available at: http://www.unaids.org/sites/default/files/media_asset/90-90-90_en.pdf. Accessed May 2, 2020

2. UNAIDS. Blind Spot. Geneva: UNAIDS; 2017. Available at: http://www.unaids.org/sites/default/files/media_asset/blind_spot_en.pdf. Accessed May 2, 2020

3. Idele P, Gillespie A, Porth T, Suzuki C, Mahy M, et al. Epidemiology of HIV and AIDS among adolescents: current status, inequities, and data gaps. J Acquir Immune Defic Syndr. 2014; 66(Suppl2): S144-53

4. Billioux VG, Chang LW, Reynolds SJ, Nakigozi G, Ssekasanvu J, Grabowski MK, Ssekubugu R, Nalugoda F, Kigozi G, Kagaayi J, Serwadda D, Gray RH, Wawer MJ. Human immunodeficiency virus care cascade among sub-populations in Rakai, Uganda: an observational study. J Int AIDS Soc. 2017; 20(1):21590.

5. Peralta L, Deeds BG, Hipszer S, Ghalib K. Barriers and facilitators to adolescent HIV testing. AIDS Patient Care STDS. 2007; 21(6):400-8.

6. Mohlabane N, Tutshana B, Peltzer K, Mwisongo A. Barriers and facilitators associated with HIV testing uptake in South African health facilities offering HIV Counselling and Testing. Health SA Gesondheid. 2016; 21: 86-95

7. Indravudh PP, Sibanda EL, d'Elbee M, Kumwenda MK, et al. 'I will choose when to test, where I want to test': investigating young people's preferences for HIV self-testing in Malawi and Zimbabwe. AIDS 2017; 31(Suppl 3): S203-S212

8. MacPhail CL, Pettifor A, Coates T, Rees H. You must do the test to know your status: attitudes to HIV voluntary counseling and testing for adolescents among South African youth and parents. Health Educ Behav. 2008;35(1):87-104

9. Yahaya LA, Jimoh AA, Balogun OR. Factors hindering acceptance of HIV/AIDS voluntary counseling and testing (VCT) among youth in Kwara State, Nigeria. Afr J Reprod Health. 2010;14(3):159-64. 
10. Hensen B, Taoka S, Lewis JJ, Weiss HA, Hargreaves J. Systematic review of strategies to increase men's HIV testing in sub-Saharan Africa. AIDS (London, England). 2014; 28(14): 2133-2145

11. Lahuerta M, Wu Y, Hoffman S, Elul B, Kulkarni SG, Remien RH, Nuwagaba-Biribonwoha H, El-Sadr W, et al. Advanced HIV disease at entry into HIV care and initiation of antiretroviral therapy during 20062011: findings from four sub-saharan African countries. Clin Infect Dis. 2014; 58(3):432-41.

12. Rosenberg NE, Mtande TK, Saidi F, Stanley C, Jere E, Paile L, Kumwenda K, Mofolo I, Ng'ambi W, Miller WC, Hoffman I, Hosseinipour M. Recruiting male partners for couple HIV testing and counselling in Malawi's option B+ programme: an unblinded randomised controlled trial. Lancet HIV. 2015; 2(11): e483-91.

13. Mohlala BK, Boily MC, Gregson S. The forgotten half of the equation: randomized controlled trial of a male invitation to attend couple voluntary counselling and testing. AIDS. 2011; 25(12):1535-41.

14. Masters SH, Agot K, Obonyo B, Napierala Mavedzenge S, Maman S, Thirumurthy H. Promoting Partner Testing and Couples Testing through Secondary Distribution of HIV Self-Tests: A Randomized Clinical Trial. PLoS Med. 2016; 13(11): e1002166.

15. Thirumurthy $\mathrm{H}$, Masters SH, Mavedzenge SN, Maman S, Omanga E, Agot K. Promoting male partner HIV testing and safer sexual decision making through secondary distribution of self-tests by HIVnegative female sex workers and women receiving antenatal and post-partum care in Kenya: a cohort study. Lancet HIV. 2016; 3(6): e266-74.

16. Matovu JKB, Kisa R, Buregyeya E, Chemusto H, Mugerwa S, Musoke W, Vrana CJ, Malek AM, Korte JE, Wanyenze RK. 'If I had not taken it [HIVST kit] home, my husband would not have come to the facility to test for HIV': HIV self-testing perceptions, delivery strategies, and post-test experiences among pregnant women and their male partners in Central Uganda. Glob Health Action. 2018;11(1):1503784.

17. Siu GE, Seeley J, Wight D. Dividuality, Masculine Respectability and Reputation: How Masculinity Affects Men's Uptake of HIV Treatment in Rural Eastern Uganda. Soc Sci Med. 2013; 89: 45-52

18. Siu GE, Wight D, Seeley J. 'Dented' and 'resuscitated' masculinities: the impact of HIV diagnosis and/or enrolment on antiretroviral treatment on masculine identities in rural eastern Uganda. SAHARA J. 2014; 11:211-21.

19. Skovdal M, Campbell C, Madanhire C, Mupambireyi Z, Nyamukapa C, Gregson S. Masculinity as a barrier to men's use of HIV services in Zimbabwe. Global Health 2011; 7:1-14.

20. Latkin CA, Knowlton AR. Social network assessments and interventions for health behavior change: a critical review. Behav Med. 2015;41(3):90-7.

21. Valente TW. Social networks and health: models, methods, and applications. Am J. Epidemiol. 2010; 172(4):488-488

22. Kagaayi J, Chang LW, Ssempijja V, Grabowski MK, Ssekubugu R, Nakigozi G, Kigozi G, Serwadda DM, Gray RH, Nalugoda F, Sewankambo NK, Nelson L, Mills LA, Kabatesi D, Alamo S, Kennedy CE, Tobian AAR, Santelli JS, Ekström AM, Nordenstedt H, Quinn TC, Wawer MJ, Reynolds SJ. Impact of 
combination HIV interventions on HIV incidence in hyperendemic fishing communities in Uganda: a prospective cohort study. Lancet HIV. 2019; 6(10): e680-e687.

23. Kong X, Kigozi G, Ssekasanvu J, Nalugoda F, Nakigozi G, Ndyanabo A, Lutalo T, Reynolds SJ, Ssekubugu R, Kagaayi J, Bugos E, Chang LW, Nanlesta P, Mary G, Berman A, Quinn TC, Serwadda D, Wawer MJ, Gray RH. Association of medical male circumcision and antiretroviral therapy scale-up with community HIV incidence in Rakai, Uganda. JAMA. 2016;316(2):182-90.

24. Chang LW, Mbabali I, Kong X, Hutton H, Amico KR, Kennedy CE, Nalugoda F, Serwadda D, Bollinger RC, Quinn TC, Reynolds SJ, Gray R, Wawer M, Nakigozi G. Impact of a community health worker HIV treatment and prevention intervention in an HIV hotspot fishing community in Rakai, Uganda (mLAKE): study protocol for a randomized controlled trial. Trials. 2017;18(1):494.

25. Ratmann O, Kagaayi J, Hall M, Golubchick T, Kigozi G, Xi X, Wymant C, Nakigozi G, Abeler-Dörner L, Bonsall D, Gall A, Hoppe A, Kellam P, Bazaale J, Kalibbala S, Laeyendecker O, Lessler J, Nalugoda F, Chang LW, de Oliveira T, Pillay D, Quinn TC, Reynolds SJ, Spencer SEF, Ssekubugu R, Serwadda D, Wawer MJ, Gray RH, Fraser C, Grabowski MK; Rakai Health Sciences Program and the Pangea HIV Consortium. Quantifying HIV transmission flow between high-prevalence hotspots and surrounding communities: a population-based study in Rakai, Uganda. Lancet HIV. 2020;7(3):e173-e183

26. Lubega M, Nakyaanjo N, Nansubuga S, Hiire E, Kigozi G, Nakigozi G, Lutalo T, Nalugoda F, Serwadda D, Gray R, Wawer M, Kennedy C, Reynolds SJ. Risk Denial and Socio-Economic Factors Related to High HIV Transmission in a Fishing Community in Rakai, Uganda: A Qualitative Study. PLoS One. 2015;10(8): e0132740.

27. Seeley JA, Allison EH. HIV/AIDS in fishing communities: challenges to delivering antiretroviral therapy to vulnerable groups. AIDS Care. 2005;17(6):688-9

28. Braun, V. and Clarke, V. Using thematic analysis in psychology. Qual Res Psychol. 2006; 3 (2): 77-101.

29. Choko AT, Nanfuka M, Birungi J, Taasi G, Kisembo P, Helleringer S. A pilot trial of the peer-based distribution of HIV self-test kits among fishermen in Bulisa, Uganda. PLoS One. 2018; 13(11): e0208191.

30. Okoboi S, Lazarus O, Castelnuovo B, Nanfuka M, Kambugu A, Mujugira A, King R. Peer distribution of HIV self-test kits to men who have sex with men to identify undiagnosed HIV infection in Uganda: A pilot study. PLoS One. 2020; 15(1): e0227741.

31. Mulubwa C, Hensen B, Phiri MM, Shanaube K, Schaap AJ, Floyd S, Phiri CR, Bwalya C, Bond V, Simwinga M, Mwenge L, Fidler S, Hayes R, Mwinga A, Ayles H; HPTN 071 (PopART) Study Team. Community based distribution of oral HIV self-testing kits in Zambia: a cluster-randomised trial nested in four HPTN 071 (PopART) intervention communities. Lancet HIV. 2019; 6(2): e81-e92.

32. Hlongwa M, Mashamba-Thompson T, Makhunga S, Muraraneza C, Hlongwana K. Men's perspectives on HIV self-testing in sub-Saharan Africa: a systematic review and meta-synthesis. BMC Public Health. 2020;20(1):66. 